\title{
Using Satellite Observations to Constrain Parameterizations of Gravity Wave Effects for Global Models
}

\author{
M. JoAn AlexAnder \\ Colorado Research Associates, Division of NorthWest Research Associates, Boulder, Colorado \\ CHRISTOPHER BARNET \\ NOAA/NESDIS/STAR, Camp Springs, Maryland
}

(Manuscript received 6 January 2006, in final form 31 July 2006)

\begin{abstract}
Small-scale gravity waves are common features in atmospheric temperature observations. In satellite observations, these waves have been traditionally difficult to resolve because the footprint or resolution of the measurements precluded their detection or clear identification. Recent advances in satellite instrument resolution coupled to innovative analysis techniques have led in the last decade to some new global datasets describing the temperature variance associated with these waves. Such satellite observations have been considered the best hope for quantifying the global properties of gravity waves needed to constrain parameterizations of their effects for global models. Although global maps of averaged gravity wave temperature variance have now been published from a variety of different instruments on Earth-orbiting platforms these maps have not provided the needed constraints. The present paper first summarizes what has been learned from traditional temporally and spatially averaged analyses of satellite gravity wave observations and why new analysis methods are needed. Then an alternative is offered to these traditional analyses that recognizes the fact that the waves occur in large-amplitude events, or wave packets, that can be analyzed individually and in a statistical sense with probability density functions. For this purpose the authors present some examples of the occurrence of short-horizontal-scale waves appearing in Atmospheric Infrared Sounder (AIRS) radiance measurements and present statistics on the wave properties compiled over 1 month of data for a geographic region over Patagonia, South America.
\end{abstract}

\section{Introduction}

Atmospheric gravity waves are common oscillations that appear in measurements of wind and temperature at all altitudes in the atmosphere. They fill a broad spectrum of wave frequencies and horizontal and vertical wavenumbers, including short scales and short periods, that make them difficult to resolve in global datasets. Our understanding of the global-scale effects of these relatively small-scale waves has grown in recent years. Gravity wave forcing of the winter midlatitude circulation has been treated in weather forecasting and climate models for decades via parameterization of topographic wave drag (Lindzen 1981; Holton 1983;

Corresponding author address: M. J. Alexander, Colorado Research Associates, Division of NorthWest Research Associates, 3380 Mitchell Lane, Boulder, CO 80301.

E-mail: alexand@cora.nwra.com
Palmer et al. 1986; McFarlane 1987). Gravity waves are now known to also influence the stratospheric circulation in the spring and summer seasons (Alexander and Rosenlof 1996; Scaife et al. 2002) and in the tropical lower stratosphere (Dunkerton 1997; Giorgetta et al. 2002). Gravity waves also affect ice cloud formation with subsequent impacts on stratospheric dehydration (Jensen et al. 2001) and polar ozone loss (Carslaw et al. 1998; Dörnbrack et al. 2002; Fueglistaler et al. 2003). Parameterization of gravity wave-mean-flow forcing effects remains one of the primary means for tuning the stratospheric circulations in chemistry climate models used for studies of ozone loss and recovery (Pawson et al. 2000; Austin et al. 2003). Meanwhile, constraints for these parameterizations are sorely lacking.

The parameterization of gravity wave mean-flow forcing effects in global models varies widely in complexity. The simplest is Rayleigh friction, while the most complex parameterization schemes describe indi-

DOI: $10.1175 / J A S 3897.1$

(C) 2007 American Meteorological Society 
vidual gravity wave source events and assign wave properties to the sources in order to estimate the wave forcing effects on the atmosphere at higher altitudes. Topographic wave drag parameterizations and Rayleigh friction both slow wind speeds toward zero. Parameterization of nonorographic waves with nonzero phase speeds can also accelerate the winds. A broad spectrum of gravity wave phase speeds is needed to generate a realistic quasi-biennial oscillation in global models. Most models that treat these nonorographic waves describe their sources with a globally uniform distribution or with a smoothly varying function of latitude. A few models describe nonorographic waves emanating from specific sources (Rind et al. 1988; Shindell et al. 2001; see also Kim et al. 2003), including weather fronts (Charron and Manzini 2002) and convection (Chun et al. 2004; Beres 2004). By coupling the gravity wave sources to specific tropospheric events, these latter models link tropospheric and stratospheric climate processes with a realistic mechanism; however, our current understanding of these wave sources leaves these parameterizations with few constraints to assess the realism of the resulting effects. To test and validate the realism of these source parameterizations, detailed case studies can compare observations and source models to the parameterization predictions (Alexander et al. 2006).

The global coverage afforded by satellite observation offers the promise of global-scale constraints for gravity wave parameterization. Recent advances in satellite instrument resolution coupled to innovative analysis techniques have led in the last decade to some new global datasets describing the temperature variance associated with these waves (Fetzer and Gille 1994; Wu and Waters 1996a; Eckermann and Preusse 1999; Tsuda et al. 2000; Wu 2004). Such satellite observations have been considered the best hope for quantifying the global properties of gravity waves needed to constrain parameterizations of their effects for global models, but for several reasons, described in the next section, these maps have not provided the needed constraints.

In the present manuscript, we will first summarize what has been learned from traditional temporally and spatially averaged analyses of satellite gravity wave observations and describe why new analysis methods are needed. We then offer an alternative to these traditional analyses that recognizes the fact that the waves occur in large-amplitude events, or wave packets, that can be analyzed individually and in a statistical sense with probability density functions. For this purpose we present some examples of the occurrence of shorthorizontal-scale waves appearing in Atmospheric Infrared Sounder (AIRS) radiance measurements (Aumann and Pagano 1994) and present statistics on the wave properties compiled over 1 month of observations over a geographic region near Patagonia, South America.

\section{Brief history of satellite gravity wave analyses}

Gravity waves have been observed from space via the temperature perturbations they cause in the middle atmosphere or via associated radiance perturbations in temperature-sensitive emissions. Analyses of satellite temperature measurements for gravity waves first require the subtraction of a "background," which is defined differently for every dataset. The remaining perturbations are then assumed to be waves. From these anomalies, global maps of temperature variance have been computed (Fetzer and Gille 1994; Wu and Waters 1996a,b; Tsuda et al. 2000; Wu 2004). Instrument noise is separately assessed and may be subtracted or evaluated in comparison to the wave signals. Two examples of such analyses in the lower stratosphere are shown in Fig. 1. In the top panel, Tsuda et al. (2000) isolated short-vertical-scale perturbations in temperature profiles derived from global positioning system (GPS) beam refraction. In the bottom panel, $\mathrm{Wu}$ and Waters (1996a) isolated short-horizontal-scale perturbations in the Upper Atmosphere Research Satellite (UARS) Microwave Limb Sounder (MLS) radiances from a temperature-sensing channel.

Note that the GPS map shows peak gravity wave variances at the equator. Conversely, the UARS MLS map shows a minimum at the equator with instead a pronounced maximum in the winter jet. Subsequent research has shown that the differences in these patterns are due to the fact that the GPS analysis method included only short vertical wavelength waves, which we refer to as "slow waves," while the MLS included only very long vertical wavelength waves, or "fast waves." We describe these terms further in section 2a.

Satellite observations such as these initially offered hope that global distributions of gravity wave properties and gravity wave momentum fluxes could be derived and used to constrain gravity wave parameterizations in global models. Observations of a nearly "universal gravity wave spectrum" along with untested assumptions that the gravity wave spectrum would be "separable" (i.e., it would have the same shape in vertical wavenumber $m$ at single intrinsic frequency $\hat{\omega}$ or horizontal wavenumber $k$ ) would allow conversion of a temperature variance spectrum to a momentum flux spectrum. However, analyses of global-averaged temperature variance, such as the two examples above and others like them, do not provide the needed constraints for several reasons: 1) Since the wave spectrum is not 


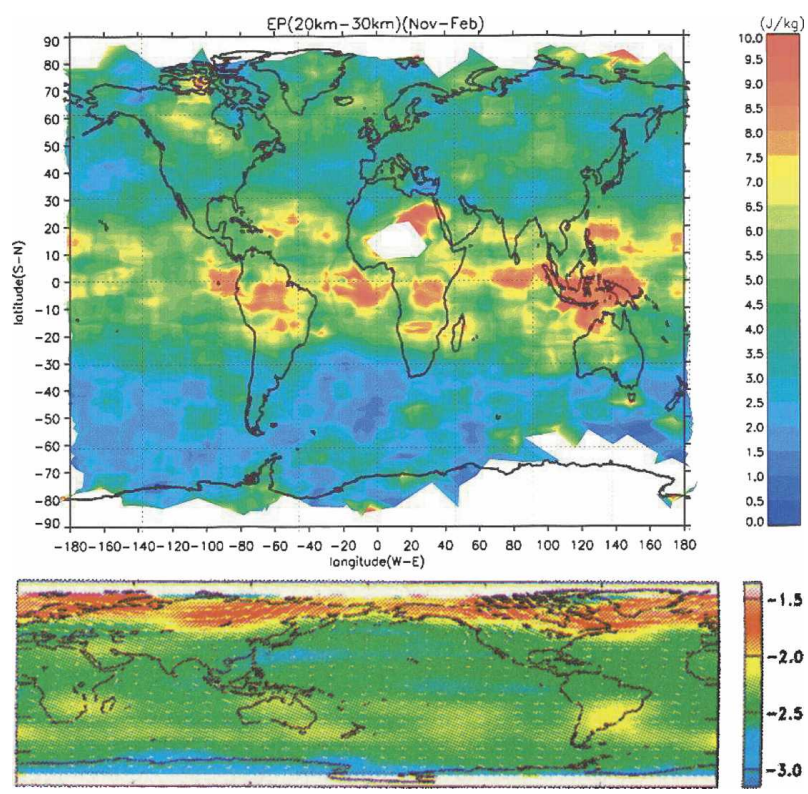

FIG. 1. (top) Average potential energy derived from shortvertical-scale gravity wave temperature variance in GPS profiles for the Nov-Feb season at 20-30-km altitude (Tsuda et al. 2000). (bottom) Short-horizontal-scale gravity wave variance $\left(\mathrm{K}^{2} \mathrm{col}-\right.$ ored in a $\log _{10}$ scale) derived from MLS radiances in a temperature sensing channel for the Dec-Feb season at 33-km altitude (Wu and Waters 1996b)

separable in $m, \hat{\omega}$, and $k$, the temperature variance is only related to wave momentum flux if simultaneous measures of wave vertical and horizontal wavelength are also determined for each measurement (Ern et al. 2004). 2) By averaging variances, we average largeramplitude wave events with weak events and low variance noise, diluting the true wave signal. 3) Each measurement technique can only see a limited portion of the true spectrum of waves that may be present because of resolution, footprint, and/or sampling limitations (see section $2 \mathrm{~b}$ ). This will be referred to here as the observational filtering effect (Alexander 1998).

Another hope has been that gravity wave satellite measurements might provide information on the locations and strengths of different gravity wave sources and help to quantify the relative importance of waves generated by topography, convection, jet instability, etc. Geographical information on convectively generated waves (McLandress et al. 2000) and topographic waves (Eckermann and Preusse 1999; Tsuda et al. 2000; Jiang et al. 2004) has been deduced from satellite temperature variance maps. These studies first considered the effects of the observational filter that gave rise to the very obvious large-scale variations in latitude and served to convincingly identify convective and topographic wave sources. However, wave amplitude infor- mation is blurred in the averaging process because the waves observed are intermittent in nature, so average variance maps fall short of providing the needed constraints for parameterizations of gravity waves in global models. We explain this with quantitative examples in the next section.

Recently, some space-based observations are being analyzed in innovative ways to try to isolate the properties of individual wave events (Dewan et al. 1998; Eckermann and Preusse 1999) and correct for the observational filter effect (Ern et al. 2004). In section 3 we describe an analysis method that determines statistical properties of wave packet events and then discuss how such wave event analyses can move us forward in constraining gravity wave parameterizations for global models.

\section{a. Fast versus slow waves}

The fast waves we refer to have fast vertical group speeds $\left(c_{g z}\right)$. Using the midfrequency approximation, linear gravity wave theory gives

$$
c_{g z} \sim \frac{-\hat{\omega}}{m} \sim \frac{-\hat{c}_{h} k}{m},
$$

where $\hat{\omega}$ is intrinsic frequency, $m$ is vertical wavenumber, $k$ is horizontal wavenumber, and $\hat{c}_{h}$ is horizontal phase speed relative to the wind. Our fast waves will therefore also tend to have 1) high intrinsic frequency, 2) long vertical wavelength, 3 ) short horizontal wavelength, and 4) high intrinsic phase speed. Slow waves will tend to have the opposite of these properties. The GPS observations shown in the top panel in Fig. 1 represent an average of the slow waves, while the MLS observations in the bottom panel represent an average of the fast waves. Fast waves will be underrepresented in long-term averages relative to their slow counterparts because the slow waves will have a higher probability of observation. The probability of observation should be inversely proportional to the vertical group speed $c_{g z}$ (Alexander et al. 2002).

We can convert the units in the two examples in Fig. 1 to average temperature amplitude to illustrate this effect of intermittency. The GPS results in the top panel show potential energy $E_{P}$ with peak values of $10 \mathrm{~J} \mathrm{~kg}^{-1}$. From Tsuda et al. (2000),

$$
E_{P}=\frac{1}{2}\left(\frac{g}{N}\right)^{2}\left(\frac{T^{\prime}}{\bar{T}}\right)^{2}
$$

where $g=9.8 \mathrm{~m}^{2} \mathrm{~s}^{-2}$ is the gravitational acceleration, $N$ is buoyancy frequency, $T^{\prime}$ is the average wave temperature perturbation, and $\bar{T}$ is the mean temperature. Choosing values characteristic of the lower strato- 


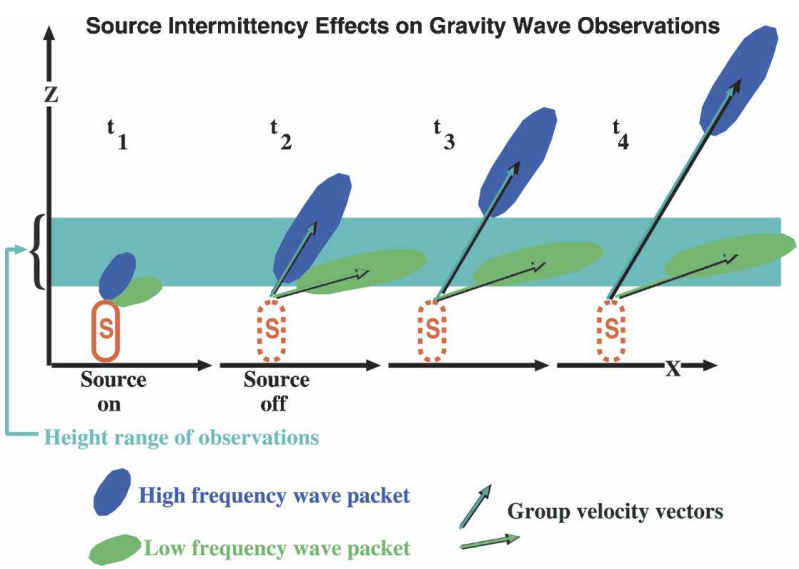

FIG. 2. Illustration of source intermittency effects on the probability of observation. Green represents a low-frequency, slow vertical group speed wave packet, while blue represents a higherfrequency fast wave packet. The red oval is an unspecified source that is no longer active after time $t_{2}$. The wave packets travel at the group velocity over sequential times $t_{1}-t_{4}$. For observations limited to the light blue height range, the slow wave would have much larger time-averaged variance than the fast wave even if their instantaneous amplitudes were equal and the fast wave carried higher momentum flux.

sphere $(N=0.02, \bar{T}=200 \mathrm{~K})$ gives peak average wave amplitudes of $\sim 2 \mathrm{~K}$ for the slow waves in the top panel of Fig. 1. This is a typical temperature amplitude observed for low-frequency waves in individual tropical radiosonde profiles (Wang and Geller 2003), suggesting that such waves are nearly always present in tropical GPS profiles. The fast waves in the bottom panel instead show peak-averaged amplitudes $T^{\prime}=\left(10^{-1.4} \mathrm{~K}^{2}\right)^{1 / 2} \sim$ $0.2 \mathrm{~K}$. One could either conclude that the amplitudes of these fast waves are 10 times smaller than the slow waves or that their occurrence is relatively intermittent and their probability of observation is low. The desired separate information on the strength of the wave events and on the intermittency in their occurrence is irretrievably blended in these time-averaged maps.

Figure 2 schematically illustrates the probability of observation effect. The slow vertical propagation speeds of the slow waves emphasized in the GPS temperature profile analysis from Tsuda et al. (2000) mean they reside in the lower stratosphere for long times, making them prominent in averaged temperature variance. These slow waves will be most prominent near the equator where the Coriolis frequency approaches zero, allowing the propagation of gravity waves with very low intrinsic frequencies and very low vertical group speeds. Further evidence suggests there is no corresponding peak in equatorial momentum flux (Ern et al. 2004; Wang and Geller 2003).

The fast waves emphasized in the UARS MLS tem- perature variance analysis from $\mathrm{Wu}$ and Waters (1996b) are instead prominent where the background winds are strong, because refraction of waves propagating upstream gives them long enough vertical wavelengths to become visible to the MLS (Alexander 1998). In the lower stratosphere, the strongest winds occur in the winter polar jet and a secondary maximum occurs in the summer subtropical jet. The UARS MLS temperature variance map therefore shows peaks in these regions because the probability of observation of long vertical wavelength waves is maximum there.

\section{b. Observational limitations for AIRS and other satellite measurements}

Figure 3 summarizes observational limitations for AIRS and other space-based gravity wave observation techniques. Schematic weighting function cross sections (ovals) are superimposed on a model field of gravity wave temperature perturbations (color background). The white contour in the lower center of the image represents a convective cloud, which was the source for the waves in the model (Holton and Alexander 1999). The four ovals on the right half of the field represent weighting function cross sections for limb sounding measurements in order of increasing vertical resolution: Limb Infrared Monitor of the Stratosphere (LIMS; Fetzer and Gille 1994), Cryogenic Infrared Spectrometers and Telescopes for the Atmosphere (CRISTA; Preusse et al. 2000), High Resolution Dynamics Limb Sounder (HIRDLS; Gille et al. 1994), and GPS (Tsuda et al. 2000). Each of these limb-viewing techniques has a long, thin weighting function, which essentially integrates along a horizontal path roughly $200 \mathrm{~km}$ long. In the plane perpendicular to the page, these limb sounders all have very narrow weighting function widths. The four ovals on the left half of the field represent weighting functions for gravity wave measurements from sublimb and nadir viewing techniques. Although the UARS MLS is a limb sounder, the methods employed by $\mathrm{Wu}$ and Waters $(1996 \mathrm{a}, \mathrm{b})$ to detect gravity waves used only data subsets when the instrument view was sub-limb. Waves were detected in these measurements via horizontal scans orthogonal to the line of sight (LOS). The LOS in this case would extend $\sim 200 \mathrm{~km}$ into the page similar to the limb sounders (see McLandress et al. 2000). The Midcourse Space Experiment (MSX) technique (Dewan et al. 1998) used a similar sub-limb view with a microwave radiometer and detector array that resolved horizontal wavelengths. Picard et al. (2002) show latitudinal variations of MSX "wave occurrence" that are similar to the latitudinal variations in UARS MLS variance. The Advanced Microwave Sounding Unit (AMSU; Wu 2004) and AIRS both ob- 


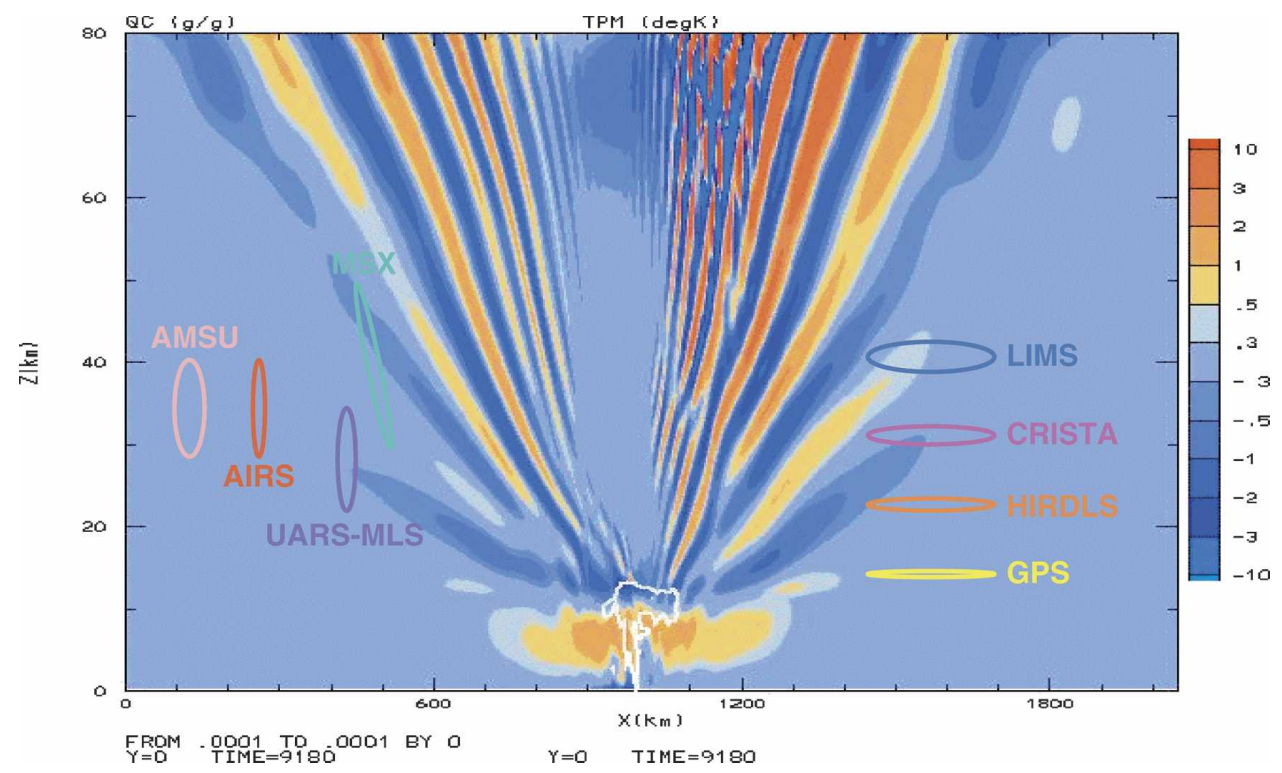

FIG. 3. Illustration of historical space-based observations of gravity waves. Background colors show temperature perturbations of modeled gravity waves (Holton and Alexander 1999) and ovals schematically representing the weighting function cross sections for different observation techniques. Note that although UARS MLS looks similar to AMSU and AIRS in this plane of the wave perturbations, AMSU and AIRS weighting functions are roughly isotropic in rotation about a vertical axis, while the MLS is elongated $200 \mathrm{~km}$ into the plane perpendicular to the page with a downward tilting axis. (See text for additional description of the weighting function dimensions in the plane perpendicular to the page.)

serve in the nadir and near-nadir sub-limb. Both instruments have temperature channels with vertical weighting function depths similar to UARS MLS but have small-horizontal-scale footprints (50 km for AMSU and $13.5 \mathrm{~km}$ for AIRS in their nadir views). Both resolve gravity waves in the two-dimensional horizontal plane (unlike MLS), and both are restricted to observing long vertical wavelength waves similar in scale to MLS.

The AIRS radiances we analyze here can resolve gravity waves with horizontal scales $>40 \mathrm{~km}$ but cannot detect waves with vertical wavelengths shorter than the full width at half maximum (FWHM) depth of the weighting functions.

\section{Local analysis of AIRS radiance perturbations}

AIRS acquires images by scanning with 90 samples ranging $\pm 49^{\circ}$ from nadir continuously along an orbit track, creating an image swath $\sim 1600 \mathrm{~km}$ wide. The data are filed in "granules" of 135 along-track samples. Each measurement includes 2378 infrared channels. Gravity wave temperature perturbations appear as radiance perturbations in channels within the $\mathrm{CO}_{2}$ 15and $4.3-\mu \mathrm{m}$ emission bands.

\section{a. Vertical wavelength limitations}

We will examine wave perturbations in the atmospheric $\mathrm{CO}_{2} 15-\mu \mathrm{m}$ emission band, specifically here at wavenumber $667.77 \mathrm{~cm}^{-1}$. Figure 4 shows the kernel function

$$
K_{\nu}(z)=\frac{1}{B_{v}} \frac{\partial B_{v}}{\partial \mathrm{T}} \frac{\partial \tau_{v}}{\partial z}
$$

where $B_{v}$ is the Planck function at frequency $\nu, T$ is temperature, and $\partial \tau_{\nu} / \partial z$ is the weighting function at frequency $\nu$. The kernel function $K_{\nu}(z)$ relates a temperature perturbation $\Delta T$ to an observed radiance perturbation $\Delta R_{\nu}$ in the linearized radiance transfer equation:

$$
\frac{\Delta R_{v}}{\mathrm{~B}_{\nu}}=\int_{z=0}^{\infty} K_{\nu}(z) \Delta T(z) d z
$$

The kernel function for the $667.77 \mathrm{~cm}^{-1}$ channel peaks near a pressure of $3 \mathrm{hPa}(\sim 40 \mathrm{~km})$ in the middle stratosphere. The FWHM depth of this function is $\sim 12 \mathrm{~km}$, which limits the waves detectable in these data to vertical wavelengths longer than $12 \mathrm{~km}$. Vertical wavelengths close to this limit will be highly attenuated, while those significantly longer will be virtually unattenuated. The right panel of Fig. 4 shows the theoretically measurable response to a wave of a given vertical wavelength with an amplitude of $1 \mathrm{~K}$. This is computed from the normalized convolution of the wave perturbation with the kernel function and is the measurable fraction of the true wave amplitude as a function of 

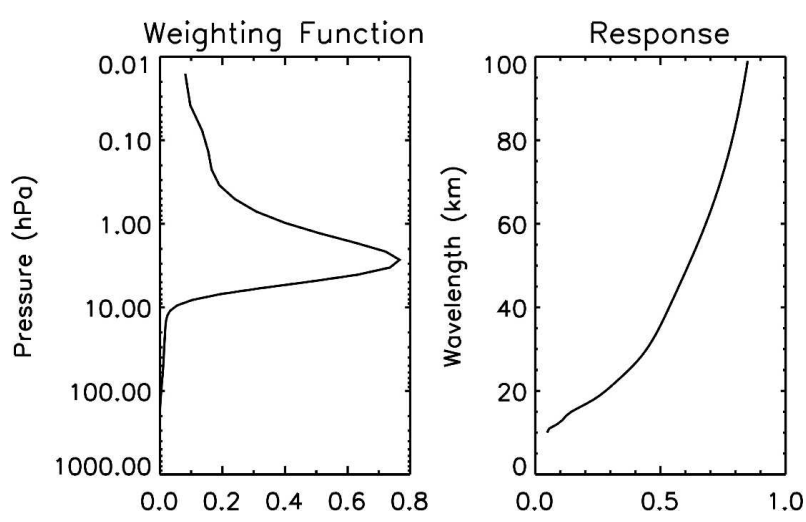

FIG. 4. (left) Kernel function (or weighting function) for the $667.77 \mathrm{~cm}^{-1}$ AIRS channel. (right) Response in this channel to a wave of amplitude unity as a function of vertical wavelength.

vertical wavelength. Note that the stated vertical resolution of AIRS of $3 \mathrm{~km}$ (Aumann et al. 2003) is much shorter than the minimum vertical wavelength visible to AIRS. The 3-km resolution is attainable only for discontinuities in temperature by utilizing the fine spectral resolution of the AIRS radiances. However, an oscillation in temperature caused by a wave with wavelength less than $\sim 12 \mathrm{~km}$ will be invisible in single-channel measurements and cannot be recovered from the multichannel retrieval method.

We can estimate the temperature perturbation associated with the radiance perturbations by assuming the atmosphere emits as a graybody in the $\mathrm{CO}_{2}$ channels; then differentiating the Planck function with respect to temperature and dividing by the background temperature gives

$$
\frac{R^{\prime}}{R}=\frac{T^{\prime}}{T}\left(\frac{h c \nu}{k T}\right),
$$

where $R^{\prime} / R$ is the fractional radiance perturbation, $h$ is Planck's constant, $c$ is the speed of light, $v$ is the wavenumber $667.8 \mathrm{~cm}^{-1}, k$ is the Boltzmann constant, $T^{\prime}$ is the temperature perturbation, and $T$ is the background temperature.

\section{b. Data selection}

A region near the Patagonian Andes of South America and northernmost Antarctic Peninsula during late winter/early spring is a known location where frequent large-amplitude gravity waves with long vertical wavelengths occur in the stratosphere (Bacmeister et al. 1990; Eckermann and Preusse 1999; McLandress et al. 2000; Wu and Jiang 2002; Wu 2004). In this region, we can thus compile some meaningful statistics on gravity waves in the AIRS data from 1 month of observa-

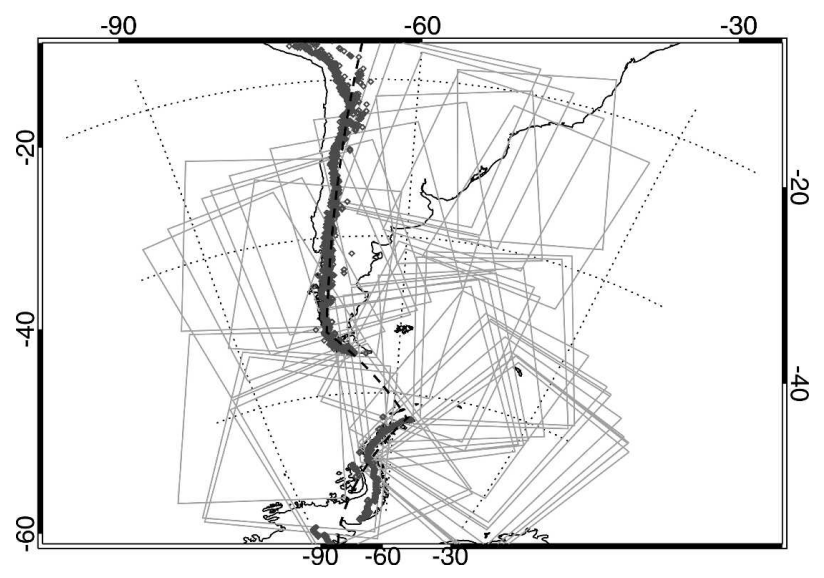

FIG. 5. Outlines of the 40 selected granules (gray boxes) projected on a map of South America and the Antarctic Peninsula. The dark gray diamond symbols trace the locations of the high point along the mountain ridges as a function of latitude. The thick dashed line, which mostly overlays these diamonds, shows our approximate definition of the mountain ridge as a function of latitude.

tions. In this section we describe our AIRS image analysis method, which gives gravity wave amplitudes, horizontal wavelengths, and propagation directions as a function of geographic location, and we present statistics on these waves for the month of September 2003. This includes analysis of 40 "granules." A granule is a patch of data with 90 pixels across the orbit path and 135 pixels along the orbit path. The selected granules all overlap the region bounded by $36^{\circ}-56^{\circ} \mathrm{S}$ latitude and $76^{\circ}-56^{\circ} \mathrm{W}$ longitude. Figure 5 shows the locations of the 40 granules projected on a map of South America and the Antarctic Peninsula.

The footprint dimensions of pixels in a granule vary with scan angle $\theta$ across the orbit path $(\Delta x)$. We approximate the geometry as

$$
\Delta x \simeq \frac{\delta_{0}}{\cos \theta}
$$

and along the orbit path $(\Delta y)$ as

$$
\Delta y \simeq \frac{\delta_{0}}{\cos (1.4 \theta)},
$$

where $\delta_{0}=13.5 \mathrm{~km}$, the footprint size at nadir.

\section{c. A local analysis method}

The first step in investigating the small-scale structure involves removing the "background variations." Raw radiances exhibit a limb-brightening effect in the cross-track direction that must be removed prior to studying smaller-scale wave perturbations. A fourthorder polynomial fit in scan angle (cross-track direction) at each along-track position was determined to be 


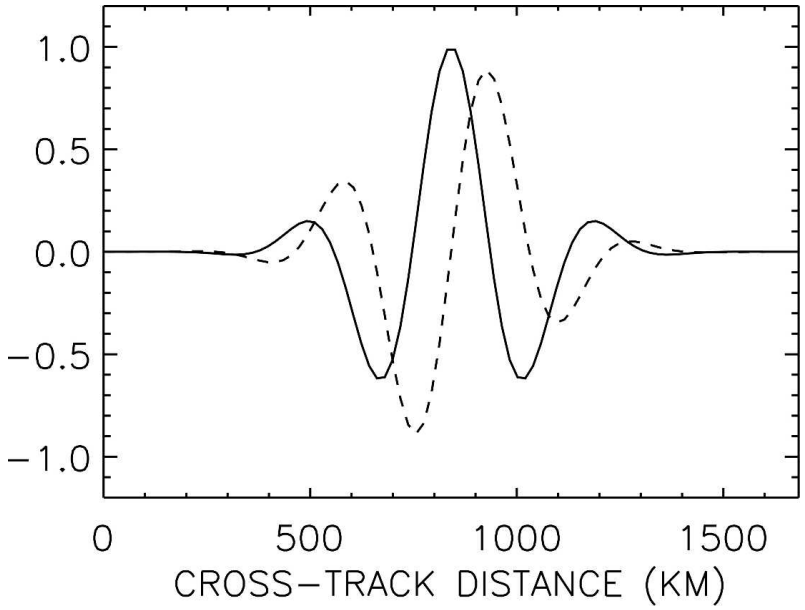

FIG. 6. Example S-transform cosine (solid) and sine (dashed) wavelet pair with scale $10 \Delta x$.

sufficient to remove the limb-brightening effect. Although this is a traditional method for removing the background ( $\mathrm{Wu} 2004$ ), a fourth-order polynomial fit will sometimes also remove some larger-scale wave perturbations. Thus for the present analysis we are limited to studying horizontal wavelengths less than $\sim 500 \mathrm{~km}$.

Because maps of average temperature variance conceal information about wave sources and local amplitudes, we have developed a wave event analysis technique using wavelet analysis tools. The results shown here utilize the S-transform wavelet (Fig. 6). The Stransform (Stockwell et al. 1996) basis functions are formed as the products of the sine (or cosine) of the wavelet scale ( $\sim$ wavelength) and a Gaussian envelope where FWHM = 1 wavelength. The sine and cosine functions remain fixed at the origin (at the left edge of the field in this case), while the Gaussian function slides in position to give the wavelet translation.

For each cross-track row $(x)$ of AIRS data, we first interpolate constant resolution equal to the average cross-track resolution $(18.9 \mathrm{~km})$ then compute the Stransform of each row and the covariance spectrum between adjacent rows. The covariance spectrum gives the cross-track wavenumber $k_{x}$, amplitude, and phase change between adjacent rows. To find the dominant wave features in each granule, we compute the average cross-track covariance spectrum for all adjacent pairs of rows in the AIRS granule then find up to five different wavelength peaks occurring in this average spectrum. We then compute the amplitude and phase for these dominant features at each location in the granule from the covariances between individual rows. The phase shift between covarying signals in adjacent rows $(\Delta \phi)$ is proportional to the along-track wavenumber $k_{y}$ of the features using the formula (Ern et al. 2004)

$$
k_{y}=\Delta \phi / \Delta y .
$$

From the wavelet analysis amplitudes, $k_{x}, k_{y}$, and the geographic orientation of the granule, we can then compute the amplitude-weighted horizontal wavenumber $k=\left(k_{x}^{2}+k_{y}^{2}\right)^{1 / 2}$ and wave propagation direction relative to the local latitude and longitude coordinate system. Figure 7 illustrates these results for granule 44 from 10 September 2003. Note that the propagation direction has a $180^{\circ}$ ambiguity, which is broken by assuming the component in the direction of the horizontal wind is always upstream. This assumption is very likely valid because the wave vertical wavelengths must be long $(\geq 12 \mathrm{~km})$ to be visible through the AIRS vertical weighting function, and the waves propagating upstream will be refracted to long vertical wavelengths while those propagating downstream will be refracted to short vertical wavelengths. The validity of this assumption will become clear from the results shown in section 4.

On any given day's worth of AIRS measurements, only a small fraction of granules show gravity waves. Most of the radiance perturbations globally are white noise. The September Patagonia region we have chosen for this study is unusual because instead a large fraction of the granules show wave perturbations. The reasons for this locus of activity are partly because of the topography in this region, which is a wave source, but partly due to observational limitations of AIRS, and we will explain this latter aspect further later in the paper.

The wavelet covariance technique clearly identifies three granules in our study as containing pure noise with no gravity wave signals. The noise granules are identifiable by their low-amplitude and very short horizontal wavelength with random propagation direction. We computed the standard deviation $\sigma_{N}$ of the noise covariance amplitude using the results of the wavelet analysis of these noise granules. All of the results shown below have been filtered to eliminate signals with covariance less than $3 \sigma_{N}$. Using (4) and $T=200 \mathrm{~K}$ gives an estimate of our noise cutoff for the $667.8 \mathrm{~cm}^{-1}$ channel as $0.39 \mathrm{~K}$, which is slightly larger than the noise equivalent $\Delta T$ for this channel of $\sim 0.3 \mathrm{~K}$ (Aumann et al. 2000).

\section{Results}

We next examine the statistics of the wave properties using probability density functions (PDFs) for either individual granules or collections of granules. Figure 8 shows PDFs of radiance amplitude versus horizontal wavelength and wave propagation angle from the horizontal wind vector, including all 40 granules in this study. Weak wave events peak at short horizontal 
(a)

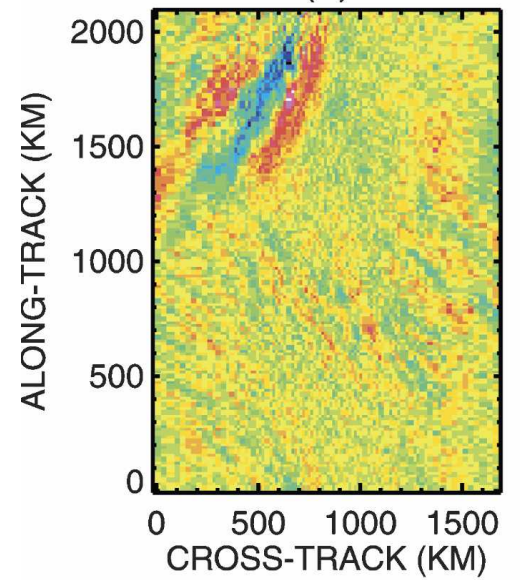

(c)

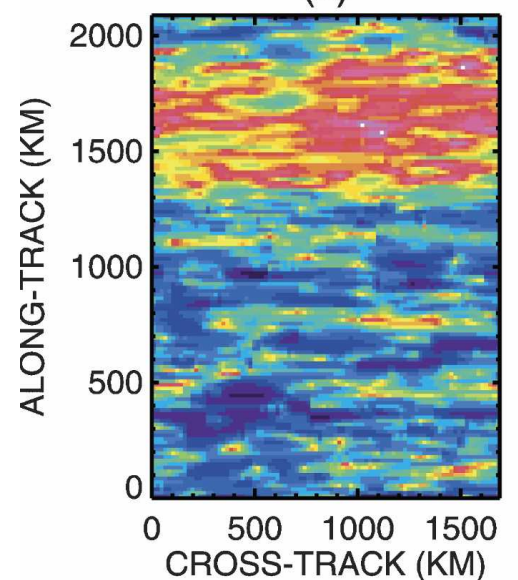

(b)
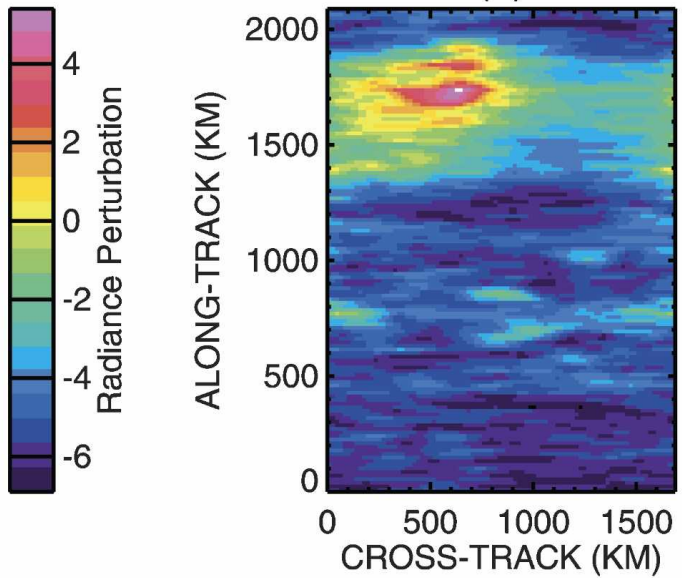

(d)

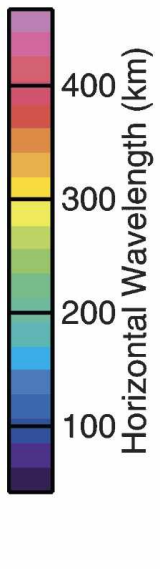

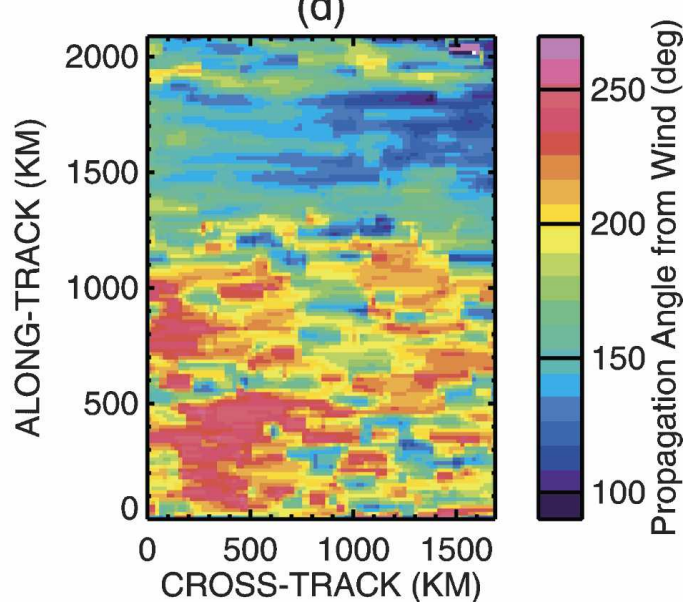

FIG. 7. Example granule wavelet analysis results: (a) radiance perturbations $\left(\mathrm{mW} \mathrm{m}^{-2} \mathrm{~cm} \mathrm{sr}^{-1}\right)$ after removal of the background limb brightening, (b) wave amplitude, (c) horizontal wavelength, and (d) propagation angle from the background wind direction $\left(180^{\circ}=\right.$ upstream propagation $)$. A radiance perturbation of \pm 4 is roughly equivalent to an apparent temperature amplitude of $\pm 3 \mathrm{~K}$.
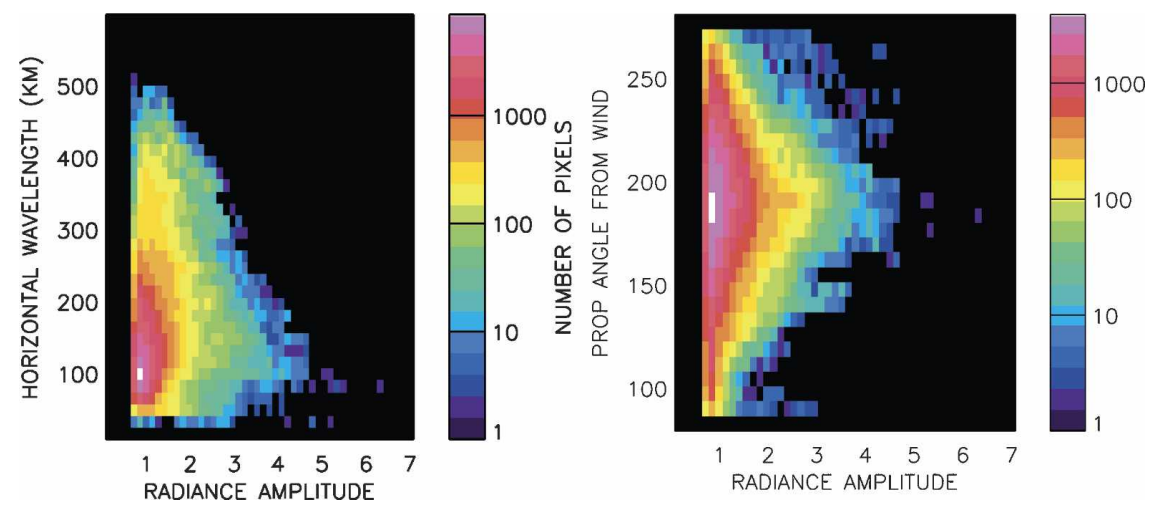

FIG. 8. Analysis results from all 40 data granules. (left) PDF of wave amplitudes ( $\mathrm{mW} \mathrm{m}^{-2}$ $\mathrm{cm} \mathrm{sr}^{-1}$ ) and horizontal wavelengths. (right) PDF of wave amplitude and propagation angle from the background horizontal wind. 

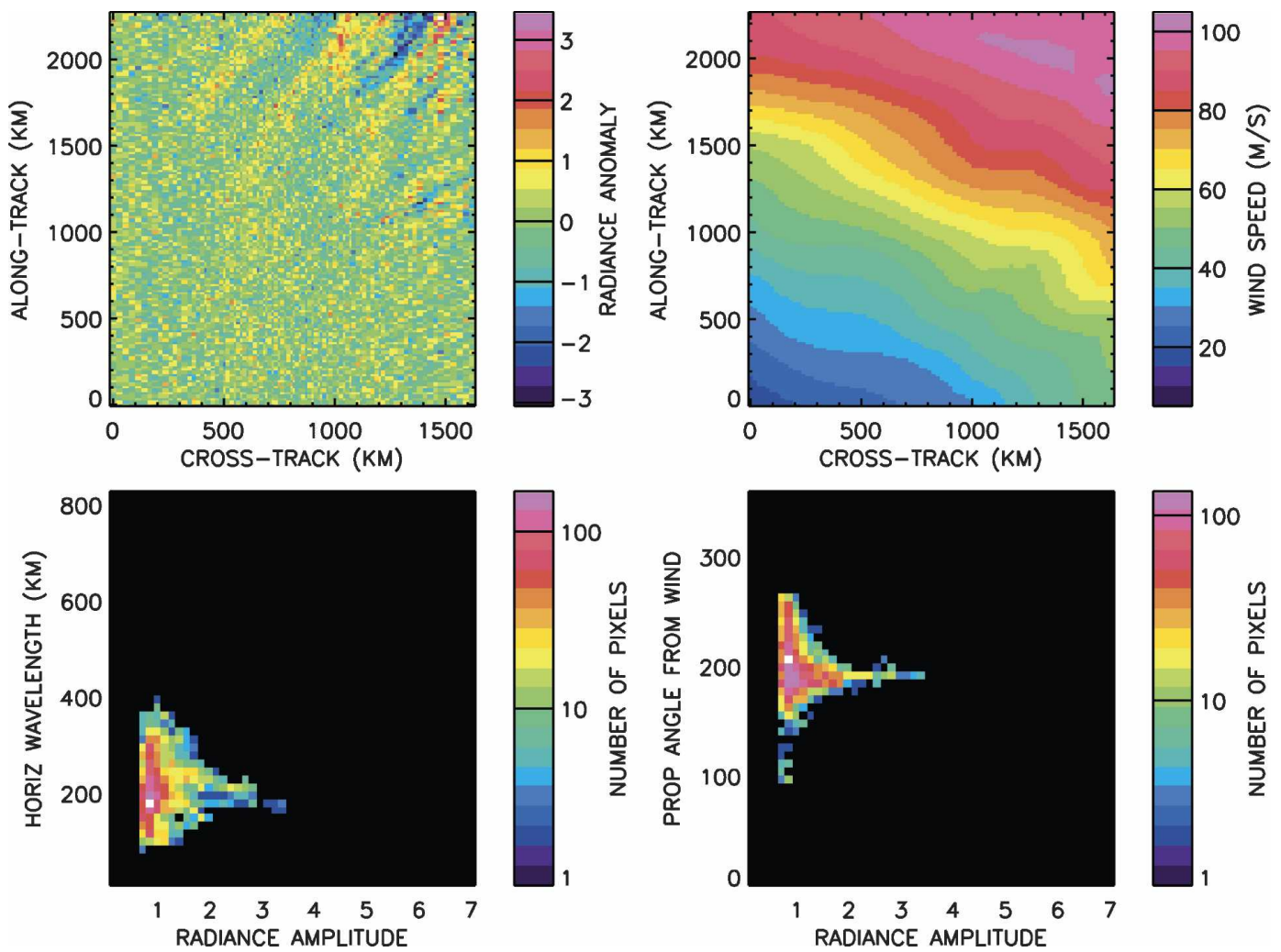

FIG. 9. Radiance perturbation ( $\mathrm{mW} \mathrm{m} \mathrm{m}^{-2} \mathrm{~cm} \mathrm{sr}^{-1}$ ), background horizontal wind speed, and PDFs same as in Fig. 8 but for a single granule from 1 Sep 2003.

wavelengths $\sim 80 \mathrm{~km}$, while strong events peak at slightly longer wavelengths $\sim 120 \mathrm{~km}$, and a broad distribution of wavelengths is observed up to $500 \mathrm{~km}$. Wave amplitudes tend to peak at a propagation direction angle near $180^{\circ}$ relative to the direction of the background horizontal wind. This most favorable angle exists because waves propagating upstream against the wind will be refracted to long vertical wavelengths and be most readily visible to (least attenuated by) the measurement technique.

\section{a. Sensitivity to background winds}

Weak events occurring far from $180^{\circ}$ in Fig. 8 are likely stronger events with short vertical wavelengths
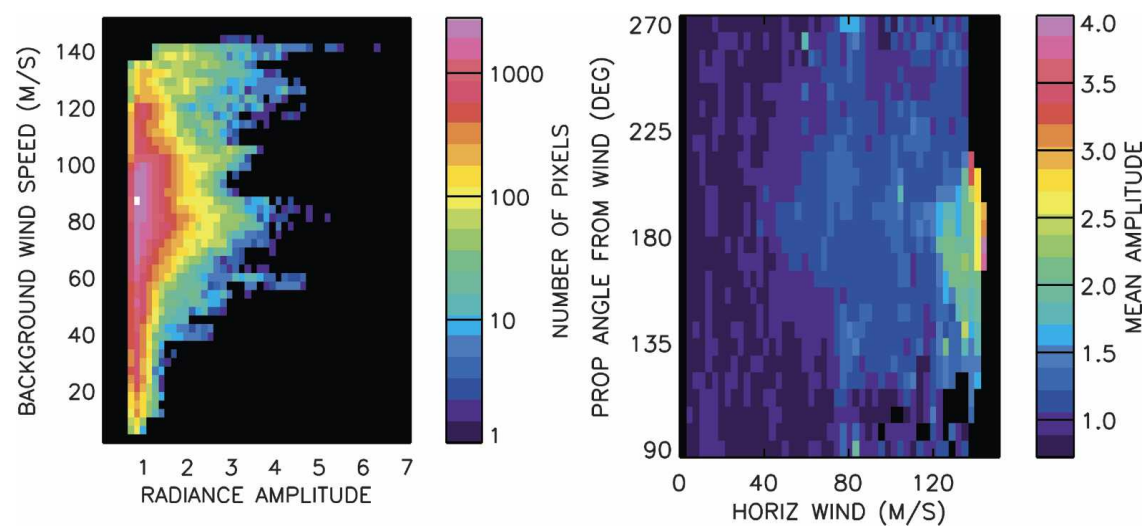

FIG. 10. (left) PDF of wave amplitudes $\left(\mathrm{mW} \mathrm{m}^{-2} \mathrm{~cm} \mathrm{sr}^{-1}\right)$ and speed of the background horizontal wind. (right) Average wave amplitude as a function of background horizontal wind and wave propagation angle relative to the wind. These plots include data from all 40 granules. 


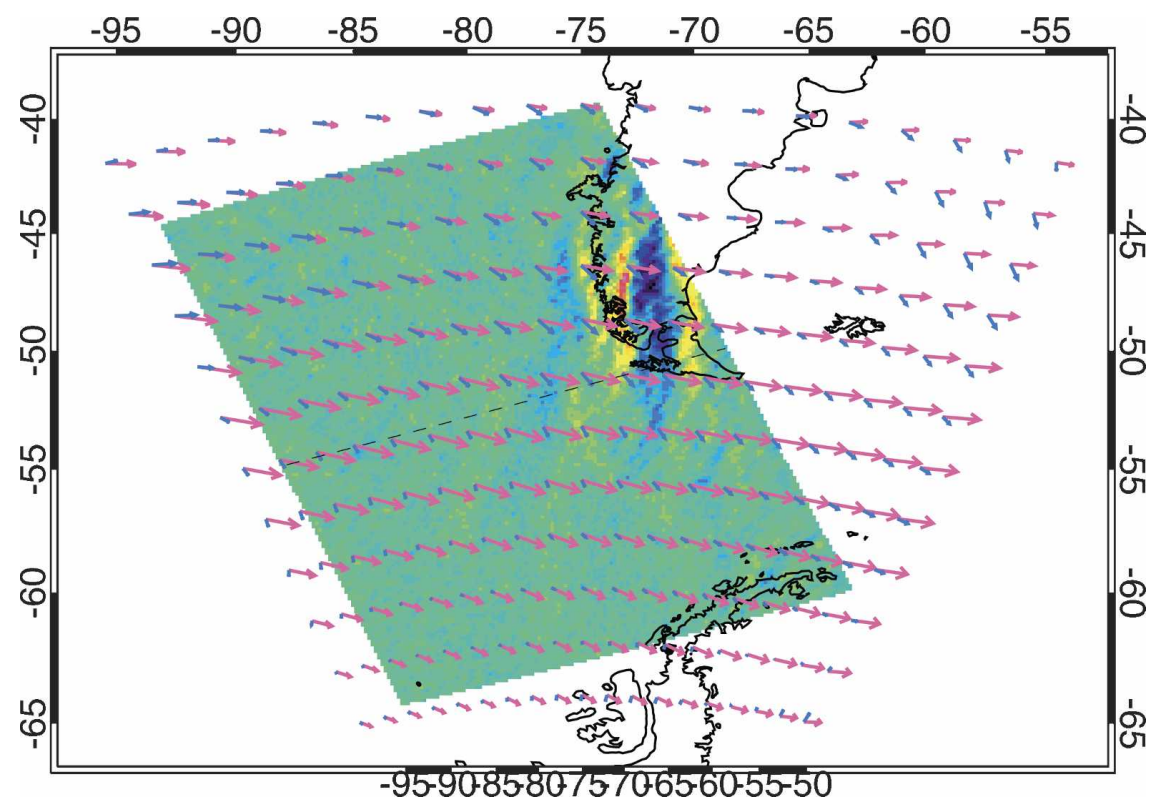

FIG. 11. Geographic projection of an example mountain wave event occurring 1 Sep 2003 over Patagonia. The dashed line represents the seam between the AIRS data granule shown in Fig. 9 and the adjacent granule to the north. Color background shows radiance perturbations superimposed on a coastline map of South America and the Antarctic Peninsula. The lower portion of the radiance image also appears in Fig. 9, which includes a color scale for reference. Pink arrows represent stratospheric wind vectors (speeds ranging $28-93 \mathrm{~m} \mathrm{~s}^{-1}$ ) and blue arrows show surface wind vectors (speeds ranging $0-22 \mathrm{~m} \mathrm{~s}^{-1}$ ).

that are highly attenuated by the measurement. Analysis of individual granules sometimes shows that the wave perturbations disappear wherever background winds are weak. Figure 9 shows an example of this. The winds shown here and in the following figures are $\mathrm{Eu}-$ ropean Centre for Medium-Range Weather Forecasts (ECMWF) analysis 4-times-daily fields with halfdegree resolution at a $40-\mathrm{km}$ altitude interpolated to the AIRS measurement locations and times.

Figure 10 shows that wave amplitudes increase dramatically with increasing horizontal wind speed above $40 \mathrm{~m} \mathrm{~s}^{-1}$. A mountain wave propagating upstream against horizontal winds of $40 \mathrm{~m} \mathrm{~s}^{-1}$ will be refracted to a vertical wavelength just longer than $12 \mathrm{~km}$, which is the approximate visibility limit due to the AIRS kernel function. The increase in wave amplitudes versus background wind above $40 \mathrm{~m} \mathrm{~s}^{-1}$ is therefore an indication that the waves in our study are primarily forced by topography, and it serves to validate our assumption that the waves propagate primarily upstream.

A geographic projection of the wave event in Fig. 9 is shown in Fig. 11. The proximity and orientation of this wave event clearly indicates its source as an Andean mountain wave. Because Fig. 9 shows that the wave perturbations disappear where the background winds fall to speeds less than $40 \mathrm{~m} \mathrm{~s}^{-1}$, the true extent of this wave event (the wave packet dimensions) may be larger than is apparent in these measurements. We also apparently miss some portion of the wave packet east of the edge of the measurement swath. This example highlights some limitations of these data that must be taken into account in future comparisons to other measurements or models of atmospheric waves.

\section{b. Investigation of wave sources}

Some of the wave events we study here occur over open ocean and far from topography, making them un-

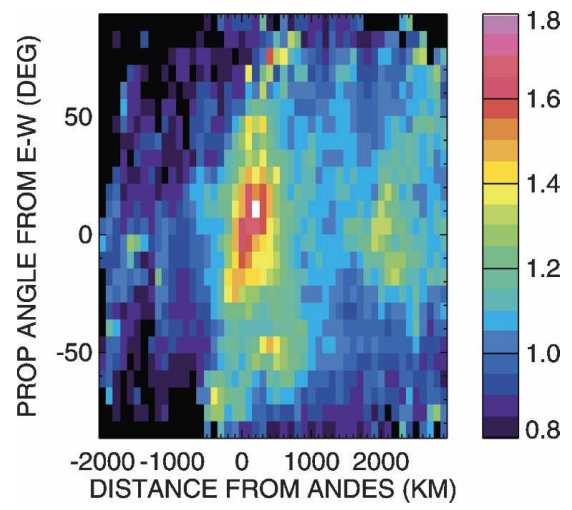

FIG. 12. Average wave amplitude as a function of distance from the mountain ridge and propagation angle from east to west. 


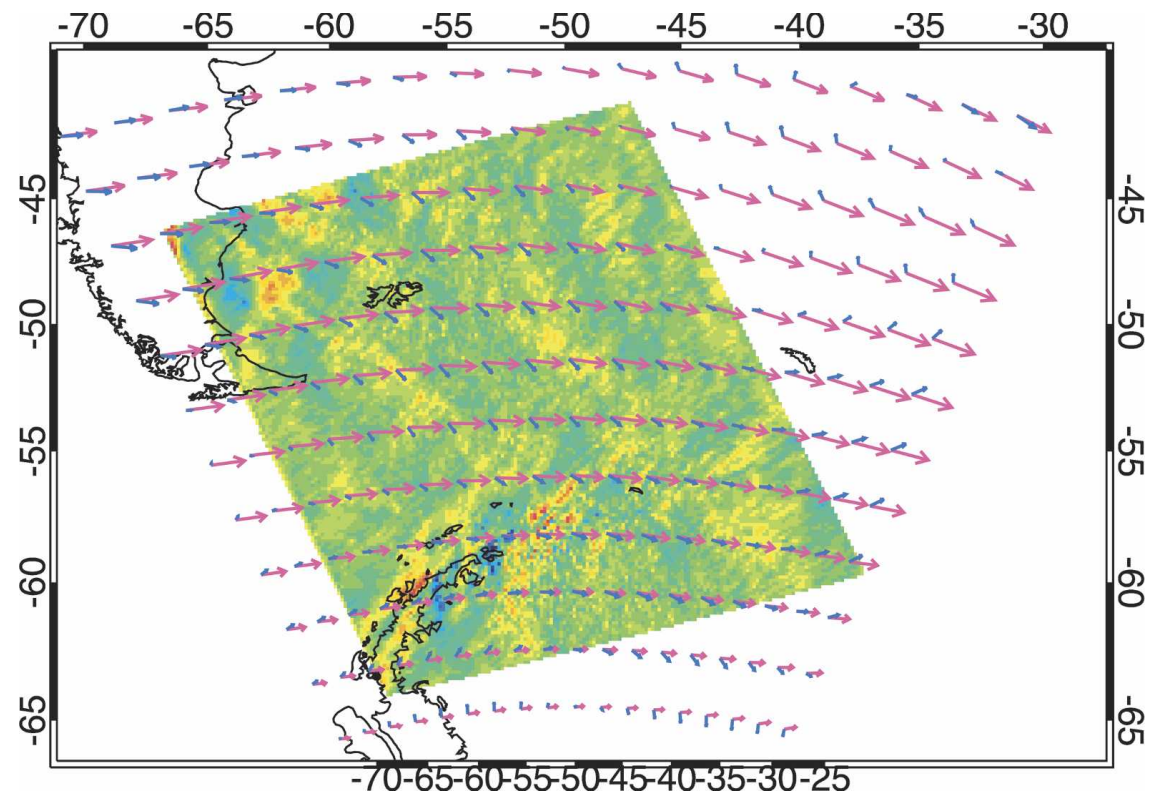

FIG. 13. Geographic projection of an example wave event off the northern tip of the Antarctic Peninsula on 10 Sep 2003. A fainter mountain wave event can also be seen in the northwest corner of the image.
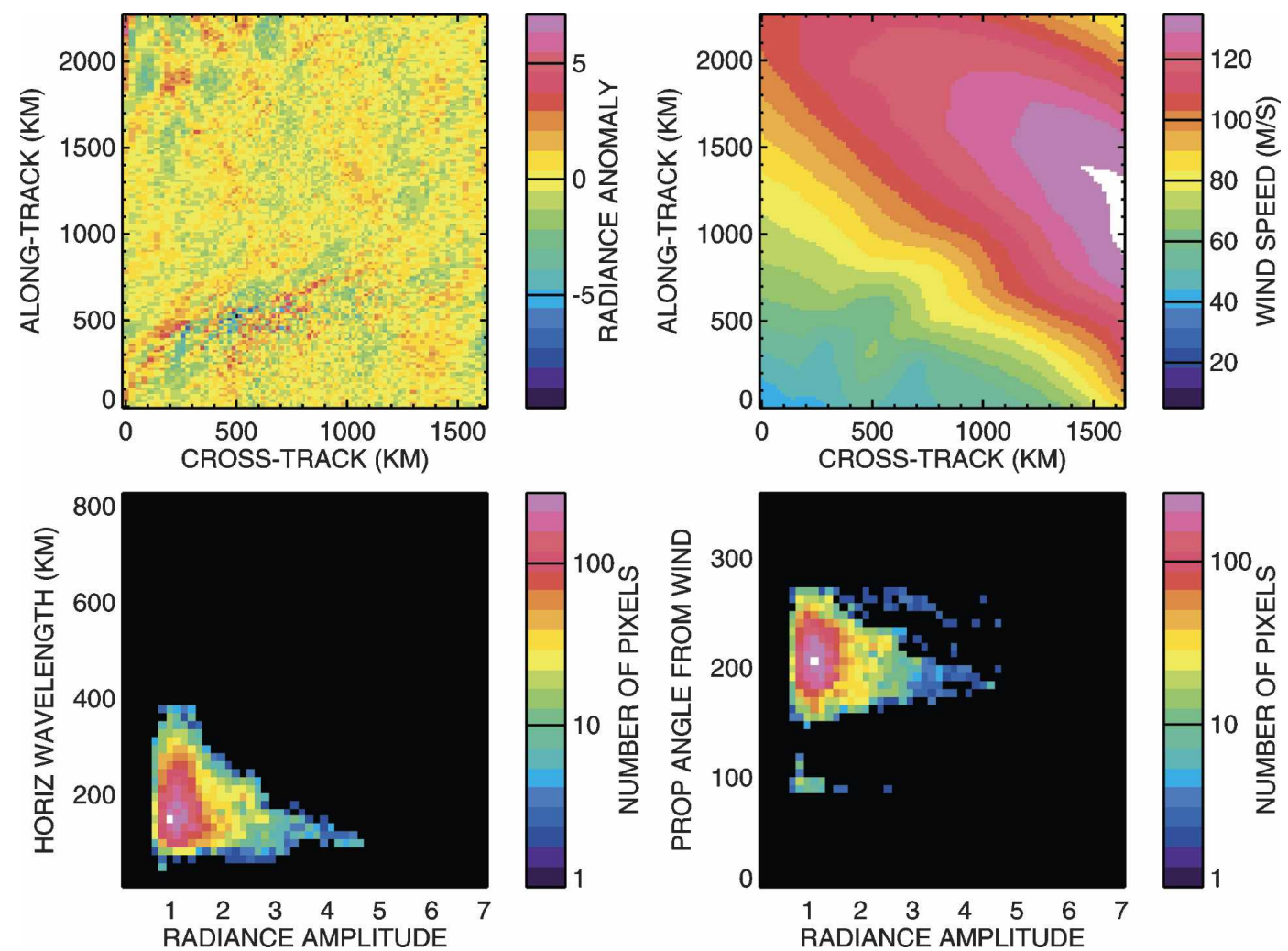

FIG. 14. Analysis of the AIRS granule shown in Fig. 13. (top left) Radiance anomaly ( $\mathrm{mW} \mathrm{m} \mathrm{m}^{-2} \mathrm{~cm} \mathrm{sr}^{-1}$ ); (top right) ECMWF wind at $3 \mathrm{hPa}$; (bottom left) PDF of radiance amplitude vs horizontal wavelength; (bottom right) $\mathrm{PDF}$ of radiance amplitude vs wave propagation direction relative to the horizontal wind vector. 


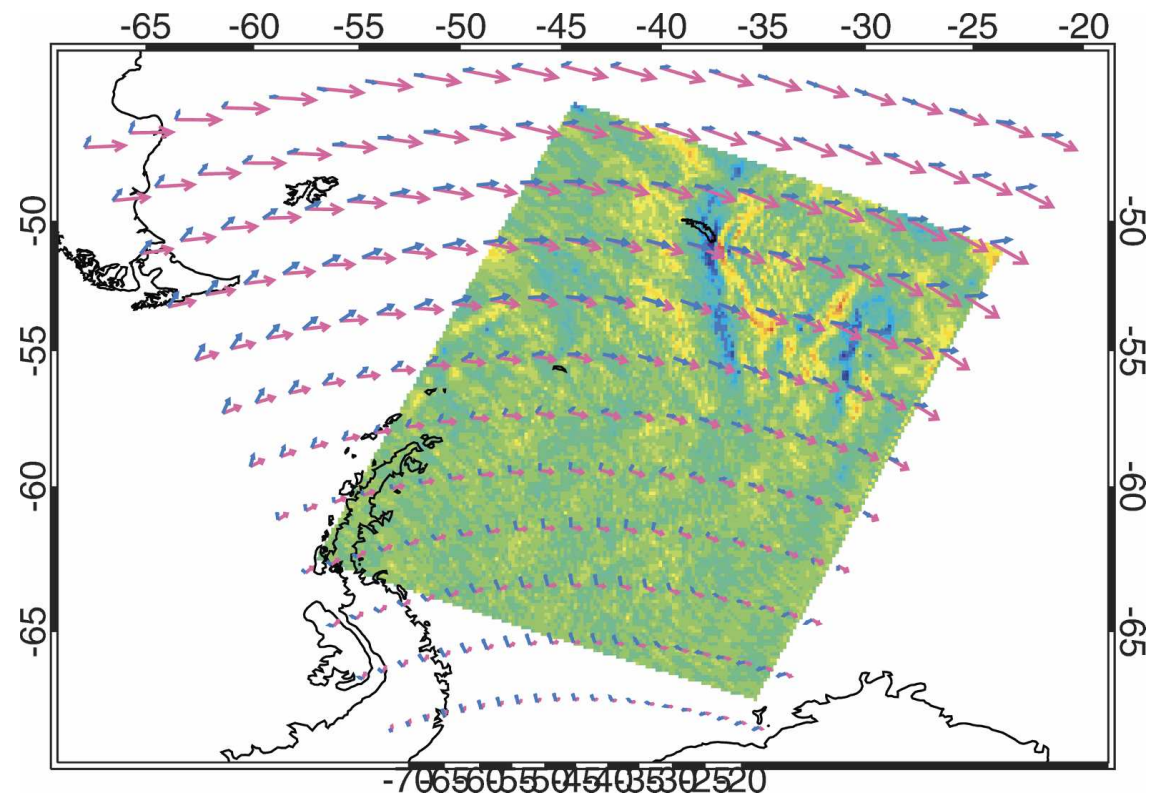

FIG. 15. Geographic projection of a wave event in the Southern Ocean on 8 Sep 2003.

likely to be mountain waves. To identify these anomalous wave events, we show the average properties of all wave events as a function of horizontal distance from the mountain ridge and propagation direction in Fig. 12. For this analysis, the mountain ridge was crudely defined as the thick dashed line in Fig. 5, which runs roughly parallel to and along the maximum altitudes of the Andes ridge within the Patagonian region in this study. The largest average amplitudes appear near $0 \mathrm{~km}$ distance and propagation angle $0^{\circ}-20^{\circ}$. This peak identifies the very commonly occurring Andean mountain wave events. Isolated smaller peaks occurring near (400 $\left.\mathrm{km},-50^{\circ}\right),\left(500 \mathrm{~km}, 80^{\circ}\right)$, and $\left(2100 \mathrm{~km}, 0^{\circ}\right)$ identify several wave events over open ocean that we highlight here with two examples that illustrate the potential of this dataset for gravity wave studies.

The region of enhanced amplitudes near $(500 \mathrm{~km}$, $\left.80^{\circ}\right)$ in Fig. 12 is associated with two wave events off the northern tip of the Antarctic Peninsula. Figure 13 shows one of these and Fig. 14 shows the analysis of this case, which includes both a weak wave event over southernmost South America as well as a wave event off the Antarctic Peninsula that includes very short horizontal-scale structure over the ocean near $60^{\circ} \mathrm{S}$ latitude. ECMWF winds (top right panel of Fig. 14) also show a large-amplitude wave at the same location and time but with a much longer horizontal wavelength. The wave occurs near a distortion in the jet suggesting the possibility that this wave could either be a mountain wave associated with island topography or generated by a jet instability mechanism. Investigation of the source mechanism for this and similar events will be the subject of future work.

A second example is responsible for the region of enhanced amplitudes at $\left(2100 \mathrm{~km}, 0^{\circ}\right)$ in Fig. 12. This case is shown in Fig. 15. No wave feature appears in the ECMWF winds in this case. This is a very strong wave event in the AIRS data and its absence in the ECMWF wind fields is surprising and also suggests further investigation with other wave source model tools.

\section{Conclusions}

The intermittent nature of gravity wave sources and gravity wave occurrence in the lower stratosphere means that time-averaged measures of their amplitudes and other properties will average large-amplitude wave events with weak events and noise and do not provide the constraints needed for gravity wave parameterizations used in global models. New analysis methods are needed to separately identify the properties of the wave events and their intermittency.

AIRS observes waves with fast vertical group speeds. Individual wave events display wave amplitudes of $3 \mathrm{~K}$ or higher. Time-averaged maps of variance of these fast waves indicate averaged wave amplitudes do not exceed $0.2 \mathrm{~K}$. The difference is due to intermittency in the occurrence of these fast waves.

The two AIRS examples presented in section 4b illustrate the potential value of AIRS data for improving our understanding of gravity wave sources and providing constraints for detailed wave source case studies 
with high-resolution models. The mountain waves that make up the bulk of the wave events in our study can also be used to constrain mountain wave source models (e.g., Bacmeister et al. 1994; Eckermann et al. 2006). Specifically, the AIRS data can constrain horizontal wavelengths, propagation directions, amplitudes, and the intermittency of mountain wave events. However, to provide these constraints, the limitations of the measurements (Fig. 4) must be carefully considered before comparing the AIRS data to any wave source models.

Observations, such as those from AIRS, can be used to validate the long vertical wavelength waves in gravity wave source models. Other datasets with smaller vertical footprints (e.g., HIRDLS, GPS) may be used to validate the shorter vertical wavelength waves generated in these source models. Once we trust these models, they can be used to develop and improve parameterizations for different gravity wave sources. This is the most likely path toward improved parameterization of gravity wave effects in global models.

Acknowledgments. This work was supported by the NASA program Earth System Science Research using data and products from Terra, Aqua, and ACRIM satellites, Grant NASA NNH04CC54C. The authors would also like to thank Dr. Sun Yung Lee for assistance in identifying periods of AIRS data useful to our study. We would also like to thank Drs. Elisa Manzini, Jadwiga Richter, and Steve Eckermann for valuable comments on drafts of this manuscript.

\section{REFERENCES}

Alexander, M. J., 1998: Interpretations of observed climatological patterns in stratospheric gravity wave variance. J. Geophys. Res., 103, 8627-8640.

—_, and K. Rosenlof, 1996: Nonstationary gravity wave forcing of the stratospheric zonal mean wind. J. Geophys. Res., 101, 23 465-23 474.

_, T. Tsuda, and R. Vincent, 2002: On the latitudinal variations observed in gravity waves with short vertical wavelengths. $J$. Atmos. Sci., 59, 1394-1404.

_, J. Richter, and B. Sutherland, 2006: Generation and trapping of gravity waves from convection with comparison to parameterization. J. Atmos. Sci., 63, 2963-2977.

Aumann, H., and R. Pagano, 1994: Atmospheric infrared sounder on Earth observing system. Opt. Eng., 33, 776-784.

— D. Gregorich, S. Gaiser, D. Hagan, R. Pagano, L. Strow, and D. Ting, 2000: AIRS algorithm theoretical basis document, level 1B, part 1: Infrared spectrometer. 70 pp. [Available online at http://eospso.gsfc.nasa.gov/eosvhomepage/ forvscientists/atbd/.]

— , and Coauthors, 2003: AIRS/AMSU/HSB on the Aqua mission: Design, science objectives, data products, and processing systems. IEEE Trans. Geosci. Remote Sens., 41, 253-264.

Austin, J., and Coauthors, 2003: Uncertainties and assessments of chemistry-climate models of the stratosphere. Atmos. Chem. Phys., 3, 1-27.

Bacmeister, J., M. Schoeberl, L. Lait, P. Newman, and B. Gary, 1990: ER-2 mountain wave encounter over Antarctica: Evidence for blocking. Geophys. Res. Lett., 17, 81-84.

— , P. Newman, B. Gary, and K. Chan, 1994: An algorithm for forecasting mountain wave-related turbulence in the stratosphere. Wea. Forecasting, 9, 241-253.

Beres, J., 2004: Gravity wave generation by a three-dimensional thermal forcing. J. Atmos. Sci., 61, 1805-1815.

Carslaw, K., and Coauthors, 1998: Increased stratospheric ozone depletion due to mountain-induced atmospheric waves. $\mathrm{Na}$ ture, 391, 675-678.

Charron, M., and E. Manzini, 2002: Gravity waves from fronts: Parameterization and middle atmosphere response in a general circulation model. J. Atmos. Sci., 59, 923-941.

Chun, H.-Y., I.-S. Song, J.-J. Baik, and Y.-J. Kim, 2004: Impact of a convectively forced gravity wave parameterization in NCAR CCM3. J. Climate, 17, 3530-3547.

Dewan, E., and Coauthors, 1998: MSX satellite observations of thunderstorm-generated gravity waves in mid-wave infrared images of the upper stratosphere. Geophys. Res. Lett., 25, 939-942.

Dörnbrack, A., T. Birner, A. Fix, H. Flentje, A. Meister, H. Schmid, E. Browell, and M. Mahoney, 2002: Evidence for inertia-gravity waves forming polar stratospheric clouds over Scandinavia. J. Geophys. Res., 107, 8287, doi:10.1029/ 2001JD000452.

Dunkerton, T., 1997: The role of gravity waves in the quasibiennial oscillation. J. Geophys. Res., 102, 26 053-26 076.

Eckermann, S., and P. Preusse, 1999: Global measurements of stratospheric mountain waves from space. Science, 286, 1534-1537.

— A. Dörnbrack, S. Vosper, H. Flentje, M. Mahoney, T. Bui, and K. Carslaw, 2006: Mountain wave-induced polar stratospheric cloud forecasts for aircraft science flights during SOLVE/THESEO 2000. Wea. Forecasting, 21, 42-68.

Ern, M., P. Preusse, M. J. Alexander, and C. Warner, 2004: Absolute values of gravity wave momentum flux derived from satellite data. J. Geophys. Res., 109, D20103, doi:10.1029/ 2004JD004752.

Fetzer, E. J., and J. C. Gille, 1994: Gravity wave variance in LIMS temperatures. Part I: Variability and comparison with background winds. J. Atmos. Sci., 51, 2461-2483.

Fueglistaler, S., and Coauthors, 2003: Detailed modeling of mountain wave PSCs. Atmos. Chem. Phys., 3, 697-712.

Gille, J., and Coauthors, 1994: High Resolution Dynamics Limb Sounder (HIRDLS) for the Earth Observing System. Proc. SPIE, 2266, 330-339.

Giorgetta, M., E. Manzini, and E. Roeckner, 2002: Forcing of the quasi-biennial oscillation from a broad spectrum of atmospheric waves. Geophys. Res. Lett., 29, 1245, doi:10.1029/2002GL014756.

Holton, J. R., 1983: The influence of gravity wave breaking on the general circulation of the middle atmosphere. J. Atmos. Sci., 40, 2497-2507.

— , and M. J. Alexander, 1999: Gravity waves in the mesosphere generated by tropospheric convection. Tellus, 51A-B, 45-58.

Jensen, E., L. Pfister, A. Ackerman, A. Tabazadeh, and O. Toon, 2001: A conceptual model of the dehydration of air due to freeze-drying by optically thin, laminar cirrus rising slowly across the tropical tropopause. J. Geophys. Res., 106, 17 237-17 252.

Jiang, J. H., S. D. Eckermann, D. L. Wu, and J. Ma, 2004: A search for mountain waves in MLS stratospheric limb radiances from the winter Northern Hemisphere: Data analysis 
and global mountain wave modeling. J. Geophys. Res., 109, D03107, doi:10.1029/2003JD003974.

Kim, Y.-J., S. Eckermann, and H.-Y. Chun, 2003: An overview of the past, present, and future of gravity-wave drag parameterization for numerical climate and weather prediction models. Atmos.-Ocean, 41, 65-98.

Lindzen, R. S., 1981: Turbulence and stress owing to gravity wave and tidal breakdown. J. Geophys. Res., 86, 9707-9714.

McFarlane, N. A., 1987: The effect of orographically excited gravity wave drag on the general circulation of the lower stratosphere and troposphere. J. Atmos. Sci., 44, 1775-1800.

McLandress, C., M. J. Alexander, and D. Wu, 2000: Microwave Limb Sounder observations of gravity waves in the stratosphere: A climatology and interpretation. J. Geophys. Res., 105 (D9), 11 947-11 967.

Palmer, T. N., G. J. Shutts, and R. Swinbank, 1986: Alleviation of a systematic westerly bias in general circulation and numerical weather prediction models through an orographic gravity wave drag parameterization. Quart. J. Roy. Meteor. Soc., 112, 1001-1039.

Pawson, S., and Coauthors, 2000: The GCM-Reality Intercomparison Project for SPARC (GRIPS): Scientific issues and initial results. Bull. Amer. Meteor. Soc., 81, 781-796.

Picard, R., E. Dewan, J. Brown, R. O'Neil, J. Winick, A. Blumberg, and P. Wintersteiner, 2002: Structure of radiance from an atmosphere perturbed by superposed gravity waves. Proc. SPIE, 4882, 149-161.

Preusse, P., S. Eckermann, and D. Offermann, 2000: Comparison of global distributions of zonal-mean gravity wave variance inferred from different satellite instruments. Geophys. Res. Lett., 27, 3877-3880.

Rind, D., R. Suozzo, N. K. Balachandran, A. Lacis, and G. Russell, 1988: The GISS global climate-middle atmosphere model. Part I: Model structure and climatology. J. Atmos. Sci., 45, 329-370.

Scaife, A. A., N. Butchart, C. D. Warner, and R. Swinbank, 2002: Impact of a spectral gravity wave parameterization on the stratosphere in the Met Office Unified Model. J. Atmos. Sci., 59, 1473-1489.

Shindell, D. T., G. A. Schmidt, R. L. Miller, and D. Rind, 2001: Northern Hemisphere winter climate response to greenhouse gas, ozone, solar, and volcanic forcing. J. Geophys. Res., 106, 7193-7210.

Stockwell, R., L. Mansinha, and R. Lowe, 1996: Localisation of the complex spectrum: The S-transform. J. Assoc. Explor. Geophys., 17 (3), 99-114.

Tsuda, T., M. Nishida, C. Rocken, and R. Ware, 2000: A global morphology of gravity wave activity in the stratosphere revealed by the GPS occultation data (GPS/MET). J. Geophys. Res., 105 (D6), 7257-7274.

Wang, L., and M. A. Geller, 2003: Morphology of gravity wave energy as observed from 4 years (1998-2001) of high vertical resolution U.S. radiosonde data. J. Geophys. Res., 108, 4489 , doi:10.1029/2002JD002786.

Wu, D. L., 2004: Mesoscale gravity wave variances from AMSU-A radiances. Geophys. Res. Lett., 31, L12114, doi:10.1029/2004GL019562.

_ fluctuations seen by the UARS MLS. Geophys. Res. Lett., 23, 3289-3292.

$\longrightarrow$, and — 1996b: Satellite observations of atmospheric variances: A possible indication of gravity waves. Geophys. Res. Lett., 23, 3631-3634.

—, and J. H. Jiang, 2002: MLS observation of gravity waves over Antarctica. J. Geophys. Res., 107, 4773, doi:10.1029/ 2002JD002390. 